\title{
Integrating the Thoughts and Methods of Mathematical Modelling into the Teaching of Advanced Mathematics
}

\author{
Yiying Yang \\ North China Electric Power University, Beijing, 102206
}

297974540@qq.com

Keywords: Advanced mathematics; Mathematic modelling; Teaching methods; Reform thoughts

\begin{abstract}
At present, there are many problems in the teaching and learning methods of Advanced Mathematics in China's higher education: the teaching methods is single and the course is boring, lacks fun, and students do not take the initiative to learn but are being passively indoctrinated. Aiming at these problems, This paper introduces the theory of mathematical modelling, introduces the thought of mathematical modelling and methods and then apply them into the reform of advanced mathematics of higher education. Finally, this paper provides some bold hypotheses and researches.

With the progress of science and technology as well as the society, mathematics is playing an ever enhanced role in scientific research. Some colleges and universities not only provide the course Advanced Mathematics to science majors, but also to some liberal arts majors. Learning the thoughts and methods of advanced mathematics can not only cultivate students' computing capacity, but also their logical thinking, spatial imagination ability and the ability to analyze and solve problems, so that their comprehensive quality will be improved. Therefore, advanced mathematics has become one of the most important public compulsory courses at colleges and universities. With the development of advanced mathematics, more and more problems have emerged during the teaching process. For example, in the traditional teaching mode, teachers "impart" knowledge at the class and students "listen to the teachers and take notes". In this teaching mode, the main body of teaching activities is teachers and students are always passively following the teachers, so the teaching mode is tedious and boring without fun and the "teaching" and "learning" are separated from each other. Meanwhile, mathematical modelling is vigorously developing in the United States and its thoughts and methods were introduced into the teaching in China in 1985 and become one of the main courses among college students' extracurricular activities. This paper conducts in-depth analysis of the thoughts and methods of mathematical modelling, and explores applying the thought of mathematical modelling into the reform of teaching advanced mathematics at colleges and universities.
\end{abstract}

\section{Current Development of Advanced Mathematics}

Among college courses, advanced mathematics is one of the major courses that we must pay attention to. The main purpose of advanced mathematics is to allow college students to master the mathematical logical thinking and methods, apply them to solve practical problems and improve college students' enthusiasm in learning mathematics. However, as China constantly reforms higher education, the defects of traditional advanced mathematics will be definitely gradually revealed and the main problems mainly include the several following aspects:

First of all, China's higher education is greatly influenced by the educational model of the Soviet Union, and advanced mathematics in China is well-renowned for being rigorous and abstract while not practical. Teachers mainly teach theories and the skills to solve target problems at class, but not apply mathematics in real life nor pay attention to the association between advanced mathematics and other subjects, which will definitely hinder students from improving their innovation and practical ability.

Secondly, at traditional classes of advanced mathematics, teachers occupy the main position and main teach theoretical knowledge while students are just passively following the teachers and their 
dominant positions cannot be given full play to. At such traditional class dominated by teachers, it is good for purely imparting theoretical and systematical knowledge, but students are put at the passive place and their innovation thoughts cannot be given full play to. Also, their rights to initiatively analyze and solve practical application problems are deprived, which is not conducive to improving students' ability.

Third, college students have different majors, but the learning contents, progress and even the final exam and scoring system of mathematics are the same for them, which will definitely cause the learning of advanced mathematics to be separated from knowledge of their own majors. Students of different majors are unified and such unity makes teachers of advanced mathematics follow the same way to teach students of different majors, and they even cannot well understand the association of advanced mathematics with their own majors and how to associate them. Thus, they will definitely fail to meet the requirement of different majors and technologies for advanced mathematics, which is not good for students with poor academic foundation because they cannot see the benefit of advanced mathematics and become disgusted at mathematics.

\section{Thought and Method of Establishing Mathematical Modelling}

Mathematical modelling is a very practical subject which needs to constantly summarizing practical experiences. It takes mathematics as the theoretical basis and computer as the took to analyze practical problems in real life and abstractly summarize real problems to final main factors related to the problems and neglect minor factors of the problems. Then, by boldly proposing reasonable assumption, mathematical modelling that can reflect the internal relationship of practical problems is established. Analyze and calculate the mathematical model and verify the results or conclusion in the initial practical problems. Then, through constant modification and verification, a reasonable conclusion is obtained.

There is usually no unified form of mathematical modelling methods, but for specific practical problems, the process of establish mathematical models can be basically divided into the several following steps:

Prepare the model: carefully analyzed the proposed practical problems, read relevant literatures and collect relevant data to prepare for the establishment of the model.

Propose the hypotheses: extract the main factors according to the specific features and practical background of the research objects, ignore minor factors and proposed reasonable hypotheses to practical problems through analyzing each major factor.

Establish a model: based on the proposed hypotheses, find model that can embed the quantitative relationship between each main factors of practical problems through the understanding of mathematical theories.

Calculate and analyze mode: use various mathematical calculation methods and tools, computer technologies and mathematical teaching software to calculate the quantitative relationship between various main factors within the established model of practical problems and analyze the conclusion.

Verify and modify: feedback the calculation results of analyzing the mode into the initial practical problems. If they match with the special situation, this model and the results through analysis can be used to guide practical problems; if they do not match each other with a huge gap, it is necessary to remodify the model and verify it again. Through constantly modification and verification of the model, the practical problems can be ultimately met and a reasonable conclusion can be reached.

\section{Important Significance of Applying Mathematical Modelling Thoughts and Methods into the Reform of Teaching Advanced Mathematics.}

With the rapid development of science and technology as well as the society, the information age has higher requirement for the cultivation of talents, and it is urgent to innovate and reform the traditional mathematical teaching mode. Mathematical modelling is established and modified through analysis and verification so as to solve various practical problems, and it is an innovative 
scientific research activity bridging mathematical knowledge and practical problems. To motivate students to apply the learned theoretical mathematical knowledge into various specific practical problems is the best manifestation of applying what they have learned into practice.

Construction theory of mathematical modeling also guide the students to enhance its generalization ability, refine the model from a large number of practical background or specific problems, reuse specific mathematical thought and method to study the model characteristics, then the mathematical model nested to practical problems, the pure autonomic learning knowledge and application of knowledge engineering is also in line with the knowledge, training students good cognitive structure based.

Mathematical modeling in divergent thinking, flexible use and open inquiry, conclusion: various analysis aspect, for students to provide free, broad space, big training students a wealth of imagination, sharp insight, open innovation ability and flexible application. To carry out the mathematical modeling of the competition activities, can make the students in order to fully play with the personality and publicity, which will fully stimulate the students' potential and enhance their creation ability. Mathematical modeling and application ability of students and mathematics theory knowledge together to improve the best combination, innovation consciousness and ability to create the best way is to train the student in important ways. Mathematical modeling of close contact problems, the traditional teacher centered, to the main screen, to impart knowledge and imparting knowledge teaching mode is based on realistic problems, take the student as the center, the purpose of the new teaching methods to cultivate the ability of.

In reality, the direct use of mathematical knowledge to solve specific problems is relatively rare, and how to use the language of mathematics to describe the face the reality of the problem often is not easy, if you want to use mathematical knowledge to analysis of practical problems, first of all is to practical problems from the complicated phenomenon to extract the main factors, summed up their mathematical relationship, mathematical model, mathematical model of the process or a deduction to establish and constantly improve the process, so this is a summary of deduction and verification of reasoning process modification to a combination of. We must change before learning mathematics only attach importance to the learning mode of reasoning, but be good at understanding and application of mathematical results, simplify the complicated reality, streamline complex mathematical theory, the results to the exact instructions, the intuitive display and a good example. Stressed the need to let students master the mathematical concept in Mathematics in the process of learning, with mathematical theory knowledge and methods to solve the realistic problems, so mathematical modeling applied to the teaching of higher mathematics is a very important issue.

\section{Apply Mathematical Modelling to the Thought of Teaching "Advanced Mathematics"}

Many typical cases in life and study can be solved by the theoretical mathematical knowledge. The course mathematical modelling is to train students' ability to associate practical problems in many cases with mathematical knowledge. Meanwhile, it guides students to constantly accept the ever emerging new knowledge, thought and methods according to requirements of the problems and cultivate students' initiative and mathematical modelling ability, self-improving ability and rapid response, so it is a creative learning method.

Integrate Mathematical Modelling into the Teaching of "Advanced Mathematics" by Setting "Mathematical Experiment" Course. For some freshmen who have not entered colleges for a long time, the calculus theory in advanced mathematics is very boring and abstract so if mathematics teachers just impart theoretical knowledge and concepts at class, students will very bored and have no interest in the course, not to mention digesting what they have heard. If mathematical experiments can be added to the process, it can not only arouse students' curiosity and get them involved in the experiments, but more important, improve students' understanding and practical ability of advanced mathematics. Mathematical experiments courses are mainly dominated by mathematical software, including the derivation, integral operation and some other basic computations. 
Relevant Cases can be added behind Each Chapter. At present, the reform of higher education in China takes solving practical problems as the fundamental research direction, which can cultivate students' good habit of thinking independently and arouse their enthusiasm in learning at the same time so as to strengthen their understanding of the learned knowledge. While choosing the case, teachers should choose those refined and typical cases and use modelling while teaching those contents related to practical problems so as to enhance students' understanding of establishing models through in-depth analysis and truly grasp the specific contents of advanced mathematics, not only the knowledge but also why.

Arouse Students' Enthusiasm in Learning and Mobilize Class Atmosphere. In the reform of higher education, the most important thing is to convert the identity of students from passively following the teacher to taking the initiative in learning and change the traditional teaching mode dominated by teachers. Instead, students should be inspired to get involved in the interactive class to stimulate their enthusiasm and passion in learning. It is necessary to change the previous form of following the class. In the advanced mathematical modelling, group thought is very critical. Thus, the homework should not be restricted to the classroom teacher, but according to the practical application of knowledge and students' specific conditions.

Reform the Assessment Methods. General examination pattern in Colleges and universities are papers, and the traditional 60 points for the pass line. In fact, this is adverse to improve the ability of students to apply what they have learned, and they are less likely to use their own learning knowledge to solve practical problems, the spirit of independent thinking of the students gradually fades away, which will go against the idea of our quality education and teaching reform, there is an urgent need to change, so we must change this examination method, pay attention to the ability to test students in Higher Mathematics Modeling and solving practical problems.

Deliver Lectures. The school can hold 3,4 lectures related to mathematics modelling each semester mainly to allow teachers to illustrate practical modelling cases so as to fully cultivate students' mathematical analysis ability. Through the cooperation with teachers, students can set models of advanced mathematics. At modelling guidance class, for modelling problems of moderate difficulty, students can independently complete the modelling under teachers' guidance.

Compile New Textbooks. Combine mathematical modelling with advanced mathematics can promote students' innovation ability and enhance interaction between teachers and students so as to change traditional old contents in advanced mathematics textbooks. Adding more contents of modelling related to practice is an important way to cultivate innovative talents.

\section{Case Analysis}

In the advanced mathematics class, based on the concrete examples, the idea and method of modeling are used to solve the problem. Through abstraction, hypothesis, variables, establish a mathematical relationship and so on to determine the final mathematical model and solution to solve the practical problems, this program is for students to master the thought and method of modeling, also can understand why mathematics can be used as a powerful way to solve the problem. In the teaching of derivatives that class can use the following case further analysis was applied to practical problems in the past.

Suppose a pig weighs 200 pounds and can gain 5 pounds every day after eating. The cost of feed is 45 cents and on the market, the pig can be sold at 65 cents. However, the problem is, the price will be reduced by $1 \%$ every day, so what is the best time to sell the pig.

In this practical problem, the variables include the pig's weight $\omega$ (pound), the length of time from the time to sell the pig and the final time to sell the pig is t (day), the costs of feeding the pig with $\mathrm{t}$ days is $\mathrm{C}$ (dollars), and the market price of the pig is $\mathrm{p}$ (dollars/pounds). Suppose after the pig is successfully sold, the revenue can be R (dollars), and the net value is $\mathrm{P}$ (dollars). There are other variables that cannot change, such as the initial weight of the pig. Before making the hypothesis, it is better to add variables to the units, such as:

$$
\omega=200+5 t
$$


$\mathrm{P}=0.65-0.01 \mathrm{t}$

$\mathrm{C}=0.45 \mathrm{t}$

$\mathrm{R}=\mathrm{p} \omega$

$\mathrm{P}=\mathrm{R}-\mathrm{C}$ In this problem, suppose $\mathrm{t}$ is larger than 0 and the final goal is to obtain the maximum value of the net income $P$.

$\mathrm{P}=(0.65-0.01 t) \cdot(200+5 t)-0.45 t$

Change the variables, $\mathrm{y}=\mathrm{P}, \mathrm{x}=\mathrm{t}$, so the final problem can be converted to obtain the maximum value of $S=\{x: x \geq 0\}$

$$
y=f(x)=(0.65-0.01 x)(200+5 x)-0.45 x
$$

It can be obtained that: $f^{\prime}(x)=(8-x) / 10$, then at the point $x=8, f^{\prime}(x)=0$ because the function increases within $(-\infty, 8)$ and decline within $(8,+\infty)$, then $f(8)$ is the entire maximum value of the function, and $\mathrm{x}=8$ is the point of the maximum value, $f(8)=133.20$. Therefore, we can get the answer to the problem, i.e., to sell the pig at day 8 can get the maximum benefit and the maximum benefit is 133.20 dollars.

\section{Conclusion}

It can be known from the above analysis that integrating mathematical modelling thoughts and methods in advanced mathematics teaching can cultivate college students' innovative ability and the ability to solve problems so as to meet the demands of reforming and developing higher education. Advanced mathematics teachers should also create opportunities for students and give full play to their initiative.

\section{References}

[1] Jia Xiaofeng, Yang Jin, Zhang Mingxue. Mathematical Modelling Contests for College Students and Reform of Teaching Advanced Mathematics at Colleges and Universities [J] Science Mathematics, 2000, 15 (2): 79-821.

[2] Lian Po. Thoughts and Exploration on Teaching Advanced Mathematics at Colleges and Universities [J] Research into Advanced Mathematics, 2011, 14( 2) :45-46.

[3] Tan Yongji. Integrating Mathematical Modelling Thoughts into Core Courses of Mathematics of General Education [J] Research into Advanced Mathematics, 2009, 12( 2) :8-12.

[4] iang Qiang. The necessity and practice to Integrate Mathematical Modelling Thoughts into Teaching Advanced Mathematics [J]. Wisdom, 2010, 07: 264-265.

[5] Gao Chuntao. The infiltration of Mathematical Modelling Thoughts in Advanced Mathematics [J] Northern Economy and Trade, 2010, 03:131-132.

[6] Wang Jinhua. The research and practice to Integrate Mathematical Modelling Thoughts into Teaching Advanced Mathematics [J] Journal of Xiangnan University, 2010, 02:31-33+49.

[7] Shi Ningqing, Li Rongqiu, Yan Xiaohong. The research of Integrating Mathematical Modelling Thoughts into Higher Vocational Mathematics [J] Education and Vocation, 2010, 09:116-118.

[8] Chang Hao. The thoughts on teaching reform of Integrating Mathematical Modelling Thoughts into Advanced Mathematics [J] Higher Education of Sciences, 2009, 02:36-38.

[9] Wei Chengdong, Zhou Guisheng, Xue Tingting. The exploration and practice to Integrate Mathematical Modelling Thoughts into Teaching Advanced Mathematics [J] Higher Education Forum, 2008, 04:28-30. 
[10] Yuan Yuan. The exploration to Integrate Mathematical Modelling Thoughts into Teaching Advanced Mathematics [J] Journal of Changchun Normal University, 2013, 04:138-139. 